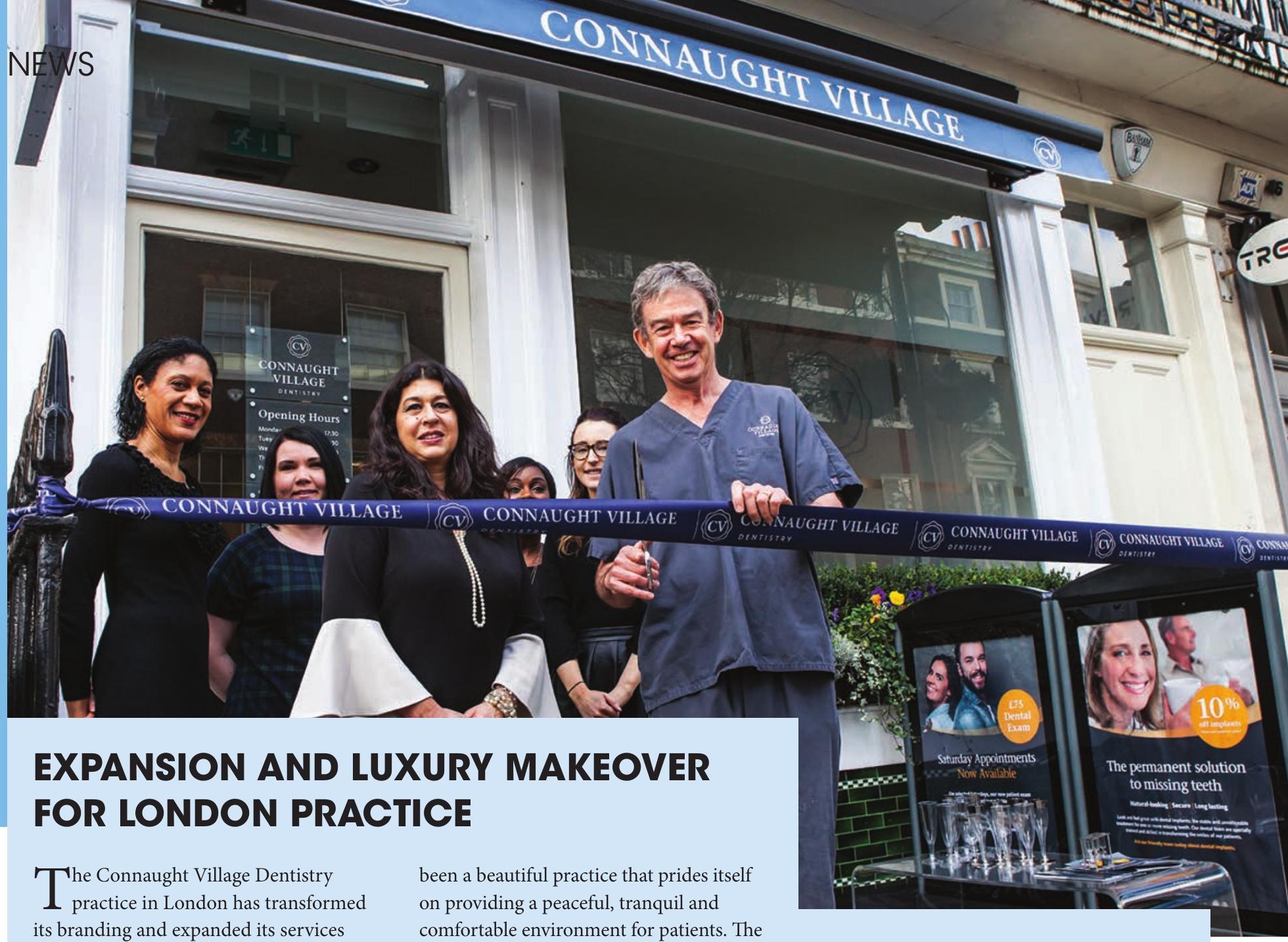
its branding and expanded its services in order to better meet the needs of its growing patient base.

The transformation has seen new luxury décor and increased Saturday services, as well as the recruitment of specialist multilingual clinicians and discounted prices for new patients.

Paula Pornaris, Practice Manager at Connaught Village Dentistry, said: 'Connaught Village Dentistry has always comfortable environment for patients. The recent makeover has enhanced this even further and we've worked really hard to enhance our luxury, high-end experience. We're delighted to be finally unveiling our new look.

'We always strive to give patients the best experience possible. From initial consultation, right the way through to our aftercare programme. As well as a new look clinic, we have also attracted new staff members to augment our highly experienced team'.

Based at 48 Connaught Street, the clinic forms part of Oasis Dental Care's Platinum group of practices, and the Connaught Village team recently hosted an official re-opening ceremony where new and existing patients were able to learn more about its wide array of dental treatments.

\title{
BSP CONFERENCE 2017 TO FOCUS ON PERFORMANCE
}

This year's British Society of Periodontology (BSP) annual conference is based on the theme of 'Performance!' with a clear focus on inspiration, innovation and pushing the boundaries in periodontal treatment.

The event will be held at King's Place in London on 22 and 23 June and will start each day with keynote speakers Dr Dan Martin of UCL Extreme Everest and Baroness Tanni Grey-Thompson, 11 gold Paralympic medal winner. Each will bring practicality and experience to the subject of personal performance - and relate this to everyday life in practice improvement and development.

To explore the subject of performance in greater depth, the conference's four main sessions also focus on ways to improve practice.

'Effecting behaviour change' will be led by Professor Susan Michie and Robert West, world experts in behaviour change, supported by Dr Birgitta Jonsson. 'Techniques for enhancing periodontal outcomes' closes the Thursday programme - led by one of the world's leading clinicians, Dr Otto Zuhr from Munich. Professor Roger Kneebone, Imperial College, will showcase his fascinating research on how we can improve our own operative outcomes from understanding artistic performance.

Friday's first session will explore improving the performance of long-term outcomes - vital for periodontal health. Professor Ola Norderd from Sweden will present lessons from his team's long-term research studies. Professor Iain

Chapple, from the University

of Birmingham, will review new digital risk assessment tools to see what they offer in managing patients with periodontal disease. Digital medicine guru Dr Maneesh Juneja will explore the future of digital medicine.

For more information visit bsperio.org.uk. 